Abstract

\title{
Investigating the Structure-Dynamics-Function Relationship in Antibodies ${ }^{\dagger}$
}

\author{
Marta Rigoli \\ Physics Department, University of Trento, Trento, Italy \\ + Presented at the Entropy 2021: The Scientific Tool of the 21st Century, 5-7 May 2021; Available online: \\ https://sciforum.net/conference/Entropy2021/.
}

Published: 5 May 2021

The paradigm that connects sequence, structure and function in proteins has been revisited in recent years, opening new perspectives on the importance of dynamics [1]. In this work we tackle this issue through the analysis of all-atom molecular dynamics (MD) simulations, with the final objective of correlating motions and structural features. We first characterize the dynamics of an antibody, through $2 \mu \mathrm{s}$ of all-atom molecular dynamics simulations, to investigate the correlation between structural features and the flexibility of the molecule. Subsequently we perform $2 \mu \mathrm{s}$ of all-atom MD simulations of the same antibody bound to its antigen, to investigate the changes in dynamics [2].

We analyzed the simulations through various different techniques among which we highlight the power of those based on the calculation of the information transfer between different amino acids [3]. These types of measurements allow us to identify significant correlations among protein regions, providing clues on the mechanism of protein function. The investigations carried out in this work also serve as a guide in the identification of those structural patterns whose preservation is necessary in the construction of coarse-grained models. Overall this study is meant as a starting point for the application of a multi-scale method to biologically relevant macromolecules.

\section{References}

1. Hensen, U.; Meyer, T.; Haas, J.; Rex, R.; Vriend, G.; Grubmüller, H. Exploring protein dynamics space: the dynasome as the missing link between protein structure and function. PLoS ONE, 2012, 7, e33931.

2. Scapin, G.; Yang, X.; Prosise, W.W.; McCoy, M.; Reichert, P.; Johnston, J.M.; Kashi, R.S.; Strickland, C. Structure of full-length human anti-PD1 therapeutic IgG4 antibody pembrolizumab. Nat. Struct. Mol. Biol. 2015, 22, 953-958.

3. Bowerman, S.; Wereszczynski, J. Detecting Allosteric Networks Using Molecular Dynamics Simulation. Methods Enzymol. 2016, 578, 429-447.

(C) 2021 by the authors. Licensee MDPI, Basel, Switzerland. This article is an open access article distributed under the terms and conditions of the Creative Commons Attribution (CC BY)

license (http://creativecommons.org/licenses/by/4.0/). 